\title{
Erratum to: Extraction equilibria and kinetics of Ti(IV) from leached chloride liquors of ilmenite
}

\author{
Abd ElAziz A. Nayl*, Hisham F. Aly
}

(c) The Nonferrous Metals Society of China and Springer-Verlag Berlin Heidelberg 2015

Erratum to: Rare Met.

\section{DOI 10.1007/s12598-015-0590-6}

Unfortunately, in the original publication of the article the author name and the mol value present in Sect. 2.2 have appeared incorrectly as below:
A. E. A. Nayl
$\ldots$ and the ionic concentration was fixed at $1.0 \mathrm{~mol} \mathrm{~L}-1$ with $\mathrm{NaClO}_{4} \ldots$

The correct author name and the mol value are given below:
A. A. Nayl $\ldots$ and the ionic concentration was fixed at $0.1 \mathrm{~mol} \mathrm{~L}^{-1}$ with $\mathrm{NaClO}_{4} \ldots$

The online version of the original article can be found under doi:10.1007/s12598-015-0590-6.

\footnotetext{
A. A. Nayl*

Chemistry Department, College of Science, Al Jouf University,

Skaka 2014, Saudi Arabia

e-mail: aanayl@yahoo.com
}

\section{A. A. Nayl - H. F. Aly}

Hot Labs Centre, Atomic Energy Authority, Cairo 13759, Egypt 